\title{
Cerebrovascular hemodynamics during pranayama techniques
}

\author{
L. Nivethitha, A. Mooventhan, N. K. Manjunath, Lokesh Bathala', Vijay K. Sharma² \\ Department of Research and Development, S-VYASA University, ' Department of Neurology, Cauvery Medical Centre, Aster CMI Hospital, \\ Bengaluru, Karnataka, India, ${ }^{2}$ Division of Neurology, National University Hospital, Singapore
}

\section{ABSTRACT}

Background: Pranayama techniques are known to produce variable physiological effects on the body. We evaluated the effect of the two commonly practiced Pranayama techniques on cerebral hemodynamics. Materials and Methods: Fifteen healthy male volunteers, trained in Yoga and Pranayama, were included in the study. Mean age was 24 years (range 2232 years). Study participants performed 2 Pranayamas in 2 different orders. Order $1(n=7)$ performed Bhastrika (bellows breaths) followed by Kumbhaka (breath retention) while order $2(n=8)$ performed Kumbhaka followed by Bhastrika. Both breathing techniques were performed for 1 min each. Continuous transcranial Doppler (TCD) monitoring was performed during the breathing techniques. TCD parameters that were recorded included peak systolic velocity (PSV), end-diastolic velocity (EDV), mean flow velocity (MFV), and pulsatility index (PI) of the right middle cerebral artery at baseline, 15, 30, 45, and 60 s. Results: Significant reductions in EDV $(3.67 \pm 6.48 ; P<0.001)$ and MFV $(22.00 \pm 7.30 ; P<0.001)$ with a significant increase in PI $(2.43 \pm 0.76 ; P<0.001)$ were observed during Bhastrika. On the contrary, a significant increase in PSV (65.27 $\pm 13.75 ; P<0.001)$, EDV $(28.67 \pm 12.03 ; P<0.001)$, and MFV $(43.67 \pm 12.85 ; P<0.001)$ with a significant reduction in PI $(0.89 \pm 0.28 ; P<0.01)$ was observed only during Kumbhaka. Conclusion: Bhastrika and Kumbhaka practices of Pranayama produce considerable and opposing effects on cerebral hemodynamic parameters. Our findings may play a potential role in designing the Pranayama techniques according to patients' requirements.

Key words: Bhastrika, cerebrovascular hemodynamics, Kumbhaka, Pranayama

\section{Introduction}

Cerebral autoregulation represents the brain's ability of maintaining cerebral perfusion over a wide range of physiological challenges. ${ }^{[1]}$ Maintenance of cerebral blood flow (CBF) ensures constant supply of nutrients and oxygen to the brain. ${ }^{[2]}$ Blood flow velocities in the major arteries of the circle of Willis can be monitored noninvasively with continuous Transcranial Doppler (TCD) and represent relative changes in CBF during short periods of physiological challenges. ${ }^{[1]}$ TCD, aptly called as the stethoscope of the brain is the

\section{Address for correspondence:}

Dr. L. Nivethitha, Department of Research and Development, S-VYASA University, Bengaluru, Karnataka, India.

E-mail: dr.nivethithathenature@gmail.com

\begin{tabular}{|l|l|}
\hline \multicolumn{2}{|c|}{ Access this article online } \\
\hline Quick Response Code: & Website: \\
\hline & www.ruralneuropractice.com \\
\cline { 2 - 2 } & \\
\hline & \\
\hline
\end{tabular}

only diagnostic tool, provides real-time monitoring of cerebrovascular hemodynamics in the major intracranial arteries. ${ }^{[3]}$

Pranayama is an ancient art of breath control, ${ }^{[4]}$ which involves breathing through one or the other nostril, holding the breath in inspiration, expiration, etc. ${ }^{[5]}$ It is one of the most important yogic practices, ${ }^{[4]}$ consists of long, sustained inhalation (Puraka), exhalation (Rechaka), and holding breath (Kumbhaka) ${ }^{[6]}$ Kumbhaka constitutes the most important part of Pranayama ${ }^{[7]}$ during which carbon dioxide $\left(\mathrm{CO}_{2}\right)$ level rises. ${ }^{[8]}$ The increase in $\mathrm{CO}_{2}$ level provides a potent vasodilatory challenge to increase $\mathrm{CBF} \cdot{ }^{[9]}$ On the contrary, reduction in $\mathrm{CO}_{2}$ induced by hyperventilation, produces vasoconstriction and reduces $\mathrm{CBF}$ in the intracranial arteries. ${ }^{[1]}$

This is an open access article distributed under the terms of the Creative Commons Attribution-NonCommercial-ShareAlike 3.0 License, which allows others to remix, tweak, and build upon the work non-commercially, as long as the author is credited and the new creations are licensed under the identical terms.

For reprints contact: reprints@medknow.com

How to cite this article: Nivethitha $L$, Mooventhan $A$, Manjunath NK, Bathala L, Sharma VK. Cerebrovascular hemodynamics during pranayama techniques. J Neurosci Rural Pract 2017;8:60-3. 
Different types of Pranayama produce different physiological responses. ${ }^{[10]}$ For example, slow Pranayama results in reduction in heart rate and blood pressure, ${ }^{[11]}$ whereas Bhastrika Pranayama (bellows type rapid and deep breathing) increases the heart rate and blood pressure. ${ }^{[10]}$ To the best of our knowledge, information regarding cerebral hemodynamic alterations during various Pranayama techniques is lacking. In this study, we evaluated the cerebrovascular hemodynamic responses during the two Pranayama techniques - Bhastrika and Kumbhaka.

\section{Materials and Methods}

\section{Subjects}

Initially, 16 healthy male volunteers, trained in Yoga and Pranayama, were recruited. However, one of them was later excluded due to insufficient experience. The 15 final participants (mean age 24 years, range 22-32 years) belonged to one of the reputed residential Yoga University in South India.

\section{Inclusion criteria}

Healthy male volunteers, aged 18 years and above, body mass index $18.5-24.99 \mathrm{~kg} / \mathrm{m}^{2}$, and practicing regular Yoga and Pranayama techniques for more than 1 year were the inclusion criteria.

\section{Exclusion criteria}

Participants with a history of any active systemic and mental illness, on regular medication for any diseases, chronic substance abuse, and not trained in Yoga and Pranayama were excluded from the study. The study protocol was approved by the Institutional Ethics Committee and a signed written informed consent was obtained from each participant.

\section{Study design}

A single group repeated measures design was used and each participant performed two Pranayama techniques (Bhastrika and Kumbhaka) in two different orders. The order of the sessions was randomized using 7 papers with the word "Bhastrika" and 8 with the word "Kumbhaka" put in an envelope and each participant drew a paper to determine their order. ${ }^{[4]}$ In the first order $(n=7)$, participants performed Bhastrika followed by Kumbhaka while in the second order $(n=8)$, performance of Kumbhaka was followed by Bhastrika. Figure 1 summarizes the study design and workflow.

\section{Assessment}

\section{Cerebrovascular hemodynamic changes}

Cerebrovascular hemodynamic changes were monitored in the right middle cerebral artery (MCA) with

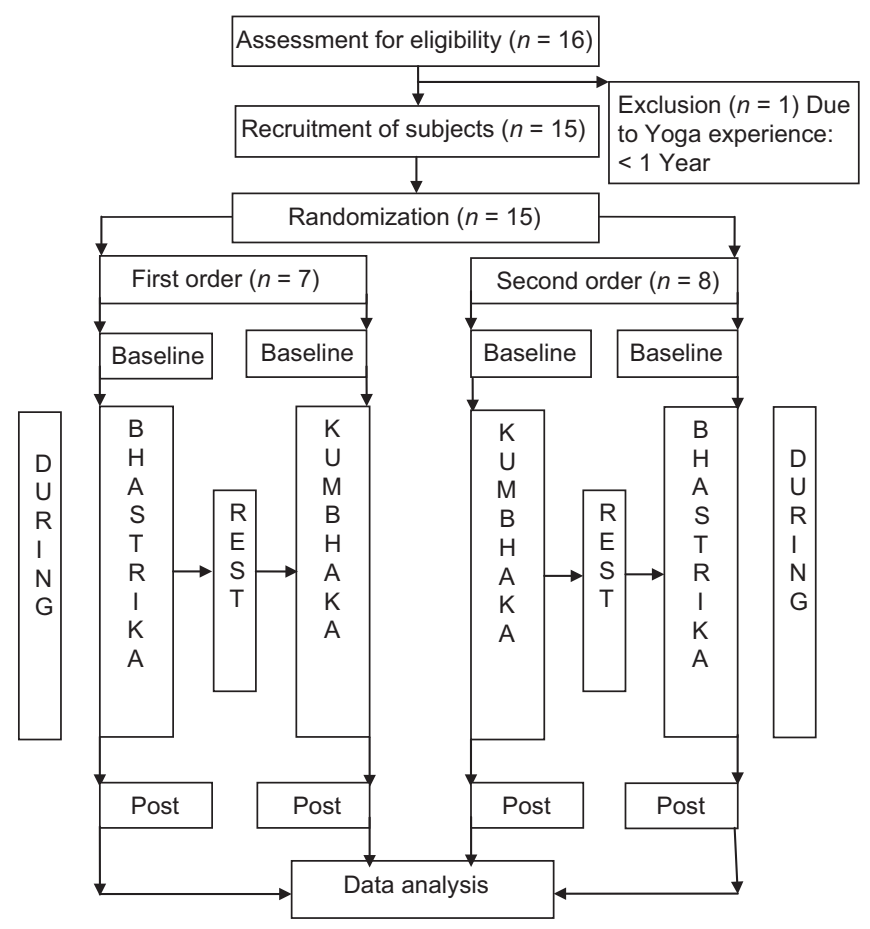

Figure 1: Study design and workflow

TCD (Multi-Dop X, DWL, Germany). A 2-MHz TCD ultrasound transducer probe was placed with the use of head frame in the right temporal area just above the zygomatic arch and in front of the tragus of the ear. The transducer was adjusted to get consistent flow spectra between 45 and $60 \mathrm{~mm}$. The right MCA was chosen only for consistency and technique of fixing the head frame and monitoring transducer. TCD parameters recorded during the monitoring included peak systolic velocity (PSV), end-diastolic velocity (EDV), mean flow velocities $(M F V)$ in $\mathrm{cm} / \mathrm{s}$, and pulsatility index (PI) ${ }^{[3]}$ These measurements were recorded at baseline, $15,30,45$, and $60 \mathrm{~s}$ during each Pranayama technique.

\section{Intervention}

Interventions were given in two different orders as described above. Each Pranayama technique was performed for $1 \mathrm{~min}$ with a rest period of $5 \mathrm{~min}$ to allow the cerebral hemodynamic patterns to settle at their baseline values.

Bhastrika (bellows breath for $1 \mathrm{~min}$ ): Participants were asked to perform voluntary forceful inhalation and forceful exhalation through both nostrils for $60 \mathrm{~s}$ followed by gentle and normal breathing.

Kumbhaka (Internal breath retention for $1 \mathrm{~min}$ ): Participants were asked to perform voluntary breath holding for $60 \mathrm{~s}$ followed by gentle and normal breathing. ${ }^{[7]}$ 
Normal breathing $(1 \mathrm{~min})$ : TCD monitoring was performed for 1 min during normal breathing pattern before and after Bhastrika and Kumbhaka.

\section{Data analysis}

Statistical analysis was performed by Student's paired samples $t$-test with the use of Statistical Package for the Social Sciences (SPSS) for Windows, Version 16.0. Chicago, SPSS Inc.

\section{Results}

All study participants demonstrated stable cerebral hemodynamic parameters during normal breathing. No significant changes were observed in PSV, EDV, MFV, and PI during normal breathing sessions. Bhastrika resulted in a significant reduction in EDV and MFV with a significant increase in PI between 15 and $60 \mathrm{~s}$ of the technique [Table 1]. Briefly, considerable reductions in EDV $(3.67 \pm 6.48 ; P<0.001)$ and MFV $(22.00 \pm 7.30$; $P<0.001)$ with a significant change in PI $(2.43 \pm 0.76$; $P<0.001)$ were observed during Bhastrika. During Kumbhaka [Table 2], a significant increase in PSV, EDV, and MFV with a significant reduction in PI was observed between 30 and $60 \mathrm{~s}$ of the breathing technique. Accordingly, a considerable increase in PSV $(65.27 \pm 13.75 ; P<0.001), \operatorname{EDV}(28.67 \pm 12.03$; $P<0.001)$, and MFV $(43.67 \pm 12.85 ; P<0.001)$ with a significant reduction in PI $(0.89 \pm 0.28 ; P<0.01)$ was observed only during Kumbhaka.

\section{Discussion}

Our study shows that Bhastrika and Kumbhaka practices of Pranayama produce considerable effects on cerebral hemodynamic parameters. $\mathrm{CBF}$ is regulated by the autonomic nervous system (ANS) by altering the tone of arteriolar sphincters. Some of the important determinants of $\mathrm{CBF}$ include partial pressure of arterial $\mathrm{CO}_{2}\left(\mathrm{PaCO}_{2}\right)$, mean arterial pressure (MAP), and cerebral metabolism. $\mathrm{PaCO}_{2}$ is the strongest regulator of arteriolar tone and an increase of $1 \mathrm{~mm}$ of Mercury $(\mathrm{Hg})$ increase $\mathrm{CBF}$ by $3-6 \%$ while a $1 \mathrm{mmHg}$ reduction decreases $\mathrm{CBF}$ by $1-3 \% .{ }^{[2]}$

We did not observe any significant change in the cerebral hemodynamic parameters during normal breath sessions, probably related to the maintenance of $\mathrm{PaCO}_{2}$, MAP, cerebral metabolism, and the balanced state of ANS within a very narrow and stable range. ${ }^{[12]}$

Hyperventilation reduces the end-tidal partial pressure of $\mathrm{CO}_{2}$ by $15.5 \pm 1.9 \mathrm{mmHg}^{[1]}$ by washing out $\mathrm{CO}_{2}$. The resultant hypocapnea increases cerebrovascular resistance and decreases the $\mathrm{CBF} .{ }^{[2]}$ We strongly believe that a similar mechanism operates during Bhastrika, resulting in a significant reduction in EDV and MFV and an increased PI between 15 and $60 \mathrm{~s}$. Our hypothesis is supported by a previous study on Bhastrika, where the sympathetic activation was reported indirectly by means of the increase in heart rate, rate pressure product, and double product. ${ }^{[10]}$ Since the arteriolar sphincters reduce the blood flow mainly by vasoconstriction-induced reduction of EDV, the effect of hyperventilation (also applicable to Bhastrika) on PSV remains poorly understood. We observed a significant reduction in PSV only after $45 \mathrm{~s}$ of rapid breathing. The cerebral hemodynamic parameters gradually returned to their baseline values within 1 min of cessation of Bhastrika, most probably related to the normalization of $\mathrm{PaCO} 2$ during the normal breathing.

During Kumbhaka, a significant increase in PSV, EDV, and MFV was observed during 30-60 s, accompanied by a significant reduction in PI. Kumbhaka might lead to the development of hypercapnia and hypoxia because previous studies on breath-holding maneuver reported a reduction

Table 1: Cerebral hemodynamic parameters during Bhastrika $(n=15)$

\begin{tabular}{lccccc}
\hline Parameter & Baseline & $15 \mathrm{~s}$ & $\mathbf{3 0 ~ s}$ & $\mathbf{4 5} \mathrm{s}$ & $\mathbf{6 0} \mathrm{s}$ \\
\hline PSV (cm/s) & $52.53 \pm 15.39$ & $51.87 \pm 15.02$ & $56.13 \pm 18.62$ & $52.53 \pm 18.21$ & $50.87 \pm 15.71$ \\
EDV (cm/s) & $21.67 \pm 7.53$ & $4.67 \pm 6.85^{*}$ & $3.80 \pm 6.57^{*}$ & $3.67 \pm 6.48^{*}$ & $5.07 \pm 6.67^{*}$ \\
MFV (cm/s) & $34.20 \pm 10.81$ & $22.87 \pm 7.93^{*}$ & $22.80 \pm 8.02^{*}$ & $22.00 \pm 7.30^{*}$ & $22.27 \pm 6.52^{*}$ \\
PI & $0.91 \pm 0.16$ & $2.26 \pm 0.88^{*}$ & $2.43 \pm 0.76^{*}$ & $2.34 \pm 0.79^{*}$ & $2.16 \pm 0.68^{*}$ \\
\hline
\end{tabular}

All values are in mean \pm SD. ${ }^{*} P<0.05$. PSV: Peak systolic velocity, EDV: End-diastolic velocity, MV: Mean flow velocity, PI: Pulsatility index, SD: Standard deviation

Table 2: Cerebral hemodynamic parameters during Kumbhaka ( $n=15)$

\begin{tabular}{lccccc}
\hline Parameter & Baseline & 15 s & 30 s & 45 s & $60 \mathrm{~s}$ \\
\hline PSV (cm/s) & $50.73 \pm 12.41$ & $50.60 \pm 11.84$ & $55.20 \pm 12.53^{*}$ & $58.60 \pm 12.57^{*}$ & $65.27 \pm 13.75^{*}$ \\
EDV (cm/s) & $17.27 \pm 7.33$ & $18.47 \pm 7.24$ & $22.67 \pm 8.24^{*}$ & $25.73 \pm 9.84^{*}$ & $28.67 \pm 12.03^{*}$ \\
MFV (cm/s) & $30.00 \pm 7.67$ & $28.93 \pm 7.04$ & $33.87 \pm 8.77^{*}$ & $38.80 \pm 10.25^{*}$ & $43.67 \pm 12.85^{*}$ \\
PI & $1.20 \pm 0.38$ & $1.11 \pm 0.34$ & $0.99 \pm 0.25^{*}$ & $0.89 \pm 0.28^{*}$ & $0.90 \pm 0.31^{*}$ \\
\hline
\end{tabular}

All values are in mean \pm SD. ${ }^{*} P<0.05$. PSV: Peak systolic velocity, EDV: End-diastolic velocity, MV: Mean flow velocity, PI: Pulsatility index, SD: Standard deviation 
of end-tidal partial pressure of oxygen below its normal level of $\sim 100 \mathrm{mmHg}$ while end-tidal $\mathrm{PaCO}_{2}$ rises above its normal level of $\sim 40 \mathrm{mmHg}$ during breath holding. ${ }^{[13]}$ Hence, we assume that the same phenomenon might have been responsible for an increase in $\mathrm{CBF}$ and reduction in cerebrovascular resistance in this present study ${ }^{[2]}$ However, lack of the objective measures such as end-tidal $\mathrm{PaCO}_{2}$ is limiting the claim for the support of the result.

The mechanism by which hypercapnia and hypoxia affect cerebrovascular resistance remains poorly understood. Cerebrovascular smooth muscles are believed to be sensitive to changes in $\mathrm{PaCO}_{2}$ and hydrogen ion $\left(\mathrm{H}^{+}\right)$ concentration. Increase in $\mathrm{CO}_{2}^{[12]}$ and hypoxia ${ }^{[2]}$ leads to increased $\mathrm{H}^{+}$concentration, which activates voltage-gated potassium $\left(\mathrm{K}^{+}\right)$channels. The resultant hyperpolarization of endothelial cells reduces intracellular calcium, leading to cerebrovascular relaxation and vasodilatation. ${ }^{[2,12]}$ Other proposed mechanisms include the release of vasoactive agents such as nitric oxide and prostaglandins in response to the velocity-induced shear stress ${ }^{[12]}$ and adenosine-induced vasodilation. ${ }^{[2]}$

Certain limitations of the study need to be acknowledged. First, we did not monitor the partial pressures of oxygen and $\mathrm{CO}_{2}$ during various Pranayama techniques to delineate the underlying physiological mechanisms for the observed changes in cerebral hemodynamic parameters. Second, we feel that monitoring of some of the autonomic variables, specifically blood pressure might have helped in a better understanding of the changes in PSV during the recovery periods of both practices. Third, our study might appear to have a small number of participants. One of the reasons for this is due to inclusion of trained professionals in Yogic Pranayama techniques. Hence, further study is required with the large sample size and more objective measurements for the better understanding.

\section{Conclusion}

Our study suggests that Bhastrika and Kumbhaka practices produced different cerebral hemodynamic changes which are almost opposite to each other. The changes were uniform among the study participants.
We hypothesize that our findings may play a potential role in designing the Pranayama techniques according to patients' requirements. We recommend further studies with all the relevant parameters in larger sample sizes for better understanding of cerebrovascular hemodynamic changes during various Pranayama techniques.

\section{Acknowledgment}

We would like to thank Mr. V. Loganathan and the staffs of Anvesana Research Laboratories, S-VYASA University, Bengaluru for their moral support.

\section{Financial support and sponsorship}

Nil.

\section{Conflicts of interest}

There are no conflicts of interest.

\section{References}

1. Yang R, Brugniaux J, Dhaliwal H, Beaudin AE, Eliasziw M, Poulin MJ, et al. Studying cerebral hemodynamics and metabolism using simultaneous near-infrared spectroscopy and transcranial Doppler ultrasound: A hyperventilation and caffeine study. Physiol Rep 2015;3. pii: E12378.

2. Willie CK, Tzeng YC, Fisher JA, Ainslie PN. Integrative regulation of human brain blood flow. J Physiol 2014;592:841-59.

3. Bathala L, Mehndiratta MM, Sharma VK. Transcranial doppler: Technique and common findings (Part 1). Ann Indian Acad Neurol 2013;16:174-9.

4. Mooventhan A, Khode V. Effect of Bhramari pranayama and OM chanting on pulmonary function in healthy individuals: A prospective randomized control trial. Int J Yoga 2014;7:104-10.

5. Malshe PC. Nisshesha rechaka pranayama offers benefits through brief intermittent hypoxia. Ayu 2011;32:451-7.

6. Srinivasan TM. Pranayama and brain correlates. Anc Sci Life 1991;11:2-6.

7. Saraswati S. Asana Pranayama Mudra Bandha. $4^{\text {th }}$ Revised Edition. Munger, Bihar, India: Yoga Publications Trust; 2008.

8. Przybylowski T, Bangash MF, Reichmuth K, Morgan BJ, Skatrud JB, Dempsey JA. Mechanisms of the cerebrovascular response to apnoea in humans. J Physiol 2003;548(Pt 1):323-32.

9. Fierstra J, Sobczyk O, Battisti-Charbonney A, Mandell DM, Poublanc J, Crawley AP, et al. Measuring cerebrovascular reactivity: What stimulus to use? J Physiol 2013;591:5809-21.

10. Madanmohan, Udupa K, Bhavanani AB, Vijayalakshmi P, Surendiran A. Effect of slow and fast pranayams on reaction time and cardiorespiratory variables. Indian J Physiol Pharmacol 2005;49:313-8.

11. Sharma VK, Trakroo M, Subramaniam V, Rajajeyakumar M, Bhavanani AB, Sahai A. Effect of fast and slow pranayama on perceived stress and cardiovascular parameters in young health-care students. Int J Yoga 2013;6:104-10.

12. Battisti-Charbonney A, Fisher J, Duffin J. The cerebrovascular response to carbon dioxide in humans. J Physiol 2011;589(Pt 12):3039-48.

13. Parkes MJ. Breath-holding and its breakpoint. Exp Physiol 2006;91:1-15. 